\title{
Editorial
}

\section{First Do No Harm: Ensuring That Healthcare Workers Vaccinate and Are Vaccinated}

\author{
Kristin L. Nichol, MD, MPH, MBA
}

In the United States, influenza and pneumococcal diseases together are responsible for 20 to 50 times more deaths due to vaccine-preventable diseases than are all other vaccine-preventable diseases combined. During the 1990 s, for example, it was estimated that more than 600,000 individuals died of influenza and pneumococcal diseases, whereas fewer than 15,000 deaths were reported for all other vaccine-preventable diseases. ${ }^{1.3}$ Vaccinations against influenza and pneumococcal diseases are safe and represent the most cost-effective means for preventing these diseases. ${ }^{4,5}$ Despite long-standing recommendations for their use, these vaccines are substantially underused in the elderly and other high-risk adult populations.

Among the priority groups targeted for annual influenza vaccination are healthcare workers, who are at risk of transmitting influenza to their high-risk patients if they work while they are ill and shedding virus. ${ }^{4,6}$ Nosocomial transmission of influenza has been well documented, as have cases in which staff have specifically been implicated as sources or vectors for the transmission of influenza to patients. In 2001 , only $36 \%$ of healthcare workers had received an influenza vaccination. ${ }^{4}$ Providing adequate educate about influenza and vaccination, facilitating easy access to vaccination, and providing vaccination without cost are important determinants of vaccination among healthcare workers. ${ }^{7-11}$

Two articles in this issue of Infection Control and Hospital Epidemiology once again highlight important issues relevant to the vaccination of healthcare workers. ${ }^{12,13}$ Martinello et al. ${ }^{13}$ report relatively high overall vaccination rates, but find that the nursing staff had lower vaccination rates than did the physician staff. Furthermore, the nursing staff were more likely to report misconceptions about influenza and vaccination. Additional efforts at education of healthcare workers, especially of nursing staff, might result in higher vaccination rates.

Lester et al. ${ }^{12}$ find that their internal medicine house staff report high rates of illness and that they are likely to work while ill, undoubtedly exposing their high-risk patients to influenza. Other investigators have also documented that healthcare workers continue working while ill, $, 7,8$ a finding that lends strong support to the recommendation for targeting healthcare workers for influenza vaccination. Lester et al. also find that barriers to vaccination included being too busy, inconvenience, and fear of side effects. Previous studies have shown similar findings, ${ }^{7-11}$ and together they suggest that facilitating convenient access to vaccination and addressing misconceptions about the safety of vaccination might be important for enhancing vaccination rates.

In addition to being important targets for vaccination themselves, healthcare workers are also critical for ensuring that other high-risk individuals are vaccinated. The study reported by Tan et al., ${ }^{14}$ also in this issue of Infection Control and Hospital Epidemiology, illustrates what can happen when healthcare providers fail to immunize their highrisk patients. This study describes an outbreak of invasive pneumococcal disease among residents of a nursing home, a phenomenon seen in other long-term-care settings. ${ }^{15-17}$ Despite a statewide policy mandating that all residents of nursing homes be assessed for their pneumococcal vaccination status and offered vaccine if not previously immunized, only $49 \%$ of the residents in this facility had been vaccinated. The attack rate among unvaccinated individuals was $16 \%$ in this outbreak (vs $0 \%$ among vaccinated individuals) with a serotype included in the current polysaccha- 
ride vaccine. This outbreak undoubtedly could have been prevented if the statewide policy had been effectively implemented. In addition to healthcare provider recommendations, systems approaches such as standing orders for implementing vaccination policies have also been associated with higher vaccination rates in a variety of healthcare settings, ${ }^{1820}$ including nursing homes. ${ }^{21,22}$

Healthcare workers are charged with adhering to the principle of "first do no harm." The intent of this dictum will be most fully realized when, in addition to being immunized themselves, healthcare workers also ensure that their high-risk patients are immunized.

\section{REFERENCES}

1. Centers for Disease Control and Prevention. Summary of notifiable diseases, United States, 2000. MMWR 2000;49(53):81-90.

2. Thompson WW, Shay DK, Weintraub E, et al. Mortality associated with influenza and respiratory syncytial virus in the United States. JAMA 2003;289:179-186.

3. Feikin DR, Schuchat A, Kolczak M, et al. Mortality from invasive pneumococcal pneumonia in the era of antibiotic resistance, 1995-1997. Am J Public Health 2000;90:223-229.

4. Centers for Disease Control and Prevention. Prevention and control of influenza: recommendations of the Advisory Committee on Immunization Practices (ACIP). MMWR 2003;52(RR-8):1-34.

5. Centers for Disease Control and Prevention. Prevention of pneumococcal disease: recommendations of the Advisory Committee on Immunization Practices (ACIP). MMWR 1997;46(RR-8):1-24

6. Centers for Disease Control and Prevention. Immunization of healthcare workers: recommendations of the Advisory Committee on Immunization Practices (ACIP) and the Hospital Infection Control Practices Advisory Committee (HICPAC). MMWR 1997;46(RR-18):1-42.

7. Weingarten $S$, Riedinger $M$, Bolton $L B$, et al. Barriers to influenza vaccine acceptance: a survey of physicians and nurses. Am J Infect Control 1989;17:202-207

8. Ohrt CK, McKinney WP. Achieving compliance with influenza immunization of medical housestaff and students: a randomized controlled trial. JAMA 1992;267:1377-1380.

9. Thomas DR, Winsted B, Koontz C. Improving neglected influenza vac- cination among healthcare workers in long-term care. J Am Geriatr Soc 1993;41:928-930.

10. Nichol KL, Hauge M. Influenza vaccination of healthcare workers. Infect Control Hosp Epidemiol 1997;18:189-194.

11. Harbarth S, Siegrist CA, Schira JC, et al. Influenza immunization: improving compliance of healthcare workers. Infect Control Hosp Epidemiol 1998;19:337-342.

12. Lester RT, McGeer A, Tomlinson G, Detsky AS. Use of, effectiveness of, and attitudes regarding influenza vaccine among house staff. Infect Control Hosp Epidemiol 2003;24:839-844.

13. Martinello RA, Jones L, Topal JE. Correlation between healthcare workers' knowledge of influenza vaccine and vaccine receipt. Infect Control Hosp Epidemiol 2003;24:845-847.

14. Tan CG, Ostrawski S, Bresnitz EA. A preventable outbreak of pneumococcal pneumonia among unvaccinated nursing home residents in New Jersey during 2001. Infect Control Hosp Epidemiol 2003;24:848-852.

15. Quick RE, Hoge CW, Hamilton DJ, et al. Underutilization of pneumococcal vaccine in nursing homes in Washington state: report of a serotype-specific outbreak and a survey. Am J Med 1993;94:149-152.

16. Centers for Disease Control and Prevention. Outbreaks of pneumococcal pneumonia among unvaccinated residents in chronic-care facilities: Massachusetts, October 1995, Oklahoma, February 1996, and Maryland, May-June 1996. MMWR 1997;46:60-62.

17. Nuorti JP, Butler JC, Crutcher JM, et al. An outbreak of multidrug-resistant pneumococcal pneumonia and bacteremia among unvaccinated nursing home residents. $N$ Engl J Med 1998;338:1861-1868.

18. Centers for Disease Control and Prevention. Vaccine-preventable diseases: improving vaccination coverage in children, adolescents, and adults. A report on recommendations from the Task Force on Community Preventive Services. MMWR 1999;48(RR-8):1-15.

19. Centers for Disease Control and Prevention. Use of standing orders programs to increase adult vaccination rates: recommendations of the Advisory Committee on Immunization Practices. MMWR 2000;49(RR1):15-24.

20. Stone EG, Morton SC, Hulscher ME, et al. Interventions that increase use of adult immunization and cancer screening services: a meta-analysis. Ann Intern Med 2002;136:641-651.

21. Nichol KL, Grimm MB, Peterson DC. Immunizations in long-term care facilities: policies and practice. J Am Geriatr Soc 1996;44:349-355.

22. Stevenson KB, McMahon JW, Harris J, et al. Increasing pneumococcal vaccination rates among residents of long-term-care facilities: providerbased improvement strategies implemented by peer-review organizations in four Western states. Infect Control Hosp Epidemiol 2000;21:705710 . 